\title{
The Cost of Shiftwork: \\ Absenteeism in a Large German Automobile Plant
}

\begin{abstract}
Using a balanced panel of some 400 organizational units in a large automobile plant, we analyze changes in absenteeism following an organizational innovation intended to improve worker health and well-being. During the period under consideration (January 2009 to December 2011) the firm replaced its traditional shift schedule that was associated with high health risks for workers by an ergonomically more advantageous system. Our estimations show that this organizational innovation was accompanied by a statistically significant and economically relevant decrease in absenteeism. However, when workers started to express discontent with the new system, management after a few months implemented another shift system that was from an ergonomic perspective again associated with higher health risks than the second one. Absence figures quickly returned to their initial levels. This suggests that leisure preferences can override health concerns in worker responses to the implementation of different shift schedules.
\end{abstract}

Keywords: Shiftwork, Absenteeism, Organizational Change

JEL-Code: M54, J22; L62 


\section{Introduction}

Shift work is common in many industries around the world. Capital-intensive production in e.g. automobile and steel plants on the one hand and the uno actu provision of services in e.g. hospitals, emergency rescue services, police and fire departments require around the clock presence of workers. In Germany, around 6.3 million employees (that is 15.6 percent of the workforce) have recently been reported to work in shifts (German Federal Statistical Office 2013). Furthermore, $42 \%$ of all manufacturing firms use some sort of shift work and about $15 \%$ of the workforce in that sector work on rotating shifts (see Jirjahn 2008: 146). However, although widespread the impact of different shift schedules/shift systems on worker well-being and individual health outcomes has not yet been studied extensively by economists (exceptions include Backes-Gellner et al. 1999 and Brachet et al. 2012). The topic has until recently remained a domain for occupational medicine.

The term "rotating shiftwork" covers a wide variety of shift schedules and implies that shifts change according to a (company-) specific schedule. These shifts can be either continuous, running 24 hours per day, 7 days a week (as in e.g. steel production and in hospitals), or semi-continuous, running 2 shifts per day, with or without weekends. The length of a shift typically varies between 8 and 12 hours, but in some cases, it can be as long as 24 hours (in e.g. emergency rescue units). Moreover, the direction of rotation can be either forward (with the clock, i.e. from morning to afternoon to night shift) or backward (against the clock, i.e. from morning to night to afternoon shift) and it can be either fast (every 1-3 days) or slow (every week or even slower).

Occupational medicine specialists have for a long time been (and continue to be) interested in the effects of shiftwork as they expect negative consequences for individual employees' physical and mental health due to disruptions to the "circadian rhythm" as 
a result of working unusual hours ${ }^{1}$. Given the negative consequences of shiftwork that have been emphasized by occupational medicine specialists it is certainly surprising, that economists and human resource specialists have so far more or less neglected these effects, because they are most likely associated with higher labor costs due to e.g. lower productivity, poorer product/service quality, more errors and lower client/customer satisfaction. However, evaluating the labor cost effects of (rotating) shiftwork has been (and continues to be) difficult, because nearly all available studies looking at the health effects of shift work rely on self-reported outcome measures. More recently, however, the research strategy asking shift workers to self-assess, first, their working conditions and, second, their impact on themselves has been considered a "major weakness" even by those working in the tradition of asking people about their subjective evaluations and mental dispositions instead of watching what these people do (e.g. Wagstaff and Sigstand-Lie 2011: 181).

To the best of our knowledge, we are the first to study the impact of a change in shift schedule on worker absenteeism - a measure we consider "objective" in the sense that it reflects workers' response to alternative shift schedules - in one particular plant of a large automobile manufacturer in Germany. The data we use gives us the opportunity to analyze the impact of a change from an ergonomically "problematic" shift system to a more "advantageous" one and vice versa (a few months after its implementation the advantageous system was again replaced by a more "problematic" one).

The remainder of the paper is structured as follows: Section 2 provides a review of the relevant literature while section 3 describes the three different shift systems used in the respective plant of the automobile company. In section 4 we present the data and some descriptive evidence while section 5 includes our econometric evidence documenting

1 Most human physical functions follow a 24-hour cycle. This cycle is called "circadian rhythm". Sleeping, waking, secretion of adrenalin and cortisol, body temperature, blood pressure, pulse and many other human body functions are all regulated by this 24-hour cycle to allow for high activity during the day and low activity during the night. 
the changes in worker behavior following the implementation of a new shift system that specialists from occupational medicine strongly favor above its predecessor as it is considered to foster worker health and well-being. Section 6 concludes.

\section{Literature Review}

A broad consensus seems to exist on the negative consequences of (rotating) shift work: First, people working on rotating shifts report more sleeping problems, poorer physical health and poorer psychological well-being than non-shift workers (e.g. Angersbach et al. 1980, Knauth et al. 1980, Koller 1983, Martens et al. 1999, Costa 1996, 2003, Åkerstedt 2003, Nakata et al. 2004). Second, shift work has been found to be detrimental to family and social life (e.g. Gray et al. 2007, Jansen et al. 2004, Root and Wooten 2008) and to lead to higher (voluntary) employee turnover (e.g. Askildsen et al. 2003). Moreover, accident risks at work have been found to be significantly higher during night hours (e.g. Hänecke et al. 1998) and the retiring age of shift workers is younger than that of non-shift workers (e.g. Shen and Dicker 2008)². Summarizing the available evidence, Dall'Ora et al. (2016) as well as Kecklund and Axelsson (2016) have recently argued that working on rotating shifts is - irrespective of speed and direction - associated with poorer employee performance and wellbeing.

However, an important issue that has rarely been addressed in the literature is the impact of different shift systems/schedules on worker behavior (such as e.g. turnover and absenteeism) 3 . Using a randomized clinical trial with 85 chemical workers ( 33 in the control and 52 in the treatment group), Czeisler et al. (1982) were among the first to show

2 Less consensus seems to exist on the positive and neutral effects of shift work. It appears, however, that shift work has no significant impact on work attitudes (e.g. Blau and Lunz 1999). Moreover, if chosen voluntarily, working night shifts seems to have no negative effects on cognitive and psychomotor performance either (e.g. Petru et al. 2005). One of the few positive effects of shift work is that for many workers with low daytime earnings an opportunity exists to self-select into shift work and supplement their earnings (e.g. Kostiuk 1990).

3 Due to differences in the data and the estimation techniques used, some papers show that shift work is associated with higher absenteeism (e.g. Chaudhury and Ng 1992, Drago and Wooden 1992, Dionne 
that workers changing the direction of rotation (i.e. moving from a backward (counterclockwise) rotating to a forward (clockwise) rotating shift schedule) experience a statistically significant increase in work schedule satisfaction and subjective health (with similar results Van Amelsvoort et al. 2004, Viitasalo et al. 2008). Moreover, these workers' productivity increased and their turnover decreased, suggesting that subjective and objective changes in behavior seem to coincide. More recently, it has been shown in lab experiments that workers on a fast-forward rotating system perform significantly better in a simulator driving exercise than those on a slow-backward rotating system (De Valck et al. 2007) and that working on a fast backward rotating schedule is associated with significantly higher levels of salivary cortisol during morning and night shifts, indicating insufficient recovery from the previous shift, than working on a fast-forward rotating schedule (Vangelova 2008). Finally, when given the choice, workers clearly prefer a rapidly forward rotating shift system with at least 16 hours of rest between shifts over its alternatives (Kecklund et al. 2008).

Summarizing the available evidence, it appears that from an occupational medicine perspective shift schedules should be designed according to now commonly accepted ergonomic criteria, recognized to limit the adverse effects on individual employees' health and wellbeing (Bambra et al. 2008, Costa 2010, Harrington 2001): First, quickly rotating (1-3 days) systems should be preferred over slowly rotating systems (weekly or longer). Second, clockwise (forward) rotation should be preferred over counterclockwise (backward) rotation and, third, large numbers of consecutive night shifts should be avoided. Taking these recommendations into account, the negative consequences of shiftwork, that typically translate into higher unit labor costs, can perhaps not be completely avoided, but at least considerably reduced.

and Dostie 2007) while others document that shift work has no impact on individuals' number of absence spells per year (e.g. Böckerman and Ilmakunnas 2008). However, since none of these studies controls for self-selection of workers, the reported findings are likely to be biased. 
Our paper fits within the genre of 'insider econometrics' that has grown in personnel economics following the seminal work on steel plants in the United States by Ichniowski, Shaw and Prennushi (1997) and on windshield installers in a large US firm by Lazear (2000). This approach emphasizes rigorous econometric analysis of panel data generated within one company or a few companies to evaluate e.g. the impact of specific human resource management practices on various measures of firm profitability and/or worker well-being (for surveys of the literature see Ichniowski and Shaw 2013, Bloom and Van Reenen 2010, Lazear and Shaw 2007, and Shaw 2009).

\section{The Shift Systems}

It is now a commonplace in the relevant literature that one of the side effects of (rotating) shiftwork is absenteeism, both real in terms of genuine sickness, and opportunistic behavior. For workers, health disruptions caused by shiftwork may have long-term consequences that eventually lead to early retirement. For companies, absenteeism is costly, inducing firms to consider the implementation of a shift system that is less detrimental to worker health (that is using forward rotation as opposed to backward rotation and avoiding consecutive weeks of night shiftwork). In the plant we study here, a backward rotating system with three consecutive weeks of night shift was replaced by a forward rotating shift schedule that was considered by occupational medicine specialists as causing fewer health risks for workers. However, the new shift system was repealed after a few months because workers started to express their (leisure related) discontent with the new schedule very soon after its implementation. In particular, workers disliked the new schedule because it resulted in a comparatively short weekend following the week on night shift. Due to the forward rotation, workers return home from the night

shift early Saturday morning and have to be back at work early Monday morning, leaving them with less than 48 hours for recovery as well as leisure and social activities over that particular weekend. 
All the organizational units in our study are located in the body shop, the paint shop or the assembly in the same plant of a large German vehicle manufacturer ${ }^{4}$. Irrespective of the shift system in use, work for the different shift teams starts at 6:30 am, 2:30 pm and 10:30 pm. At the beginning of our observation period, all units worked under a shift system that required 6 weeks of weekly rotation from day shift (D) to morning shift (M) followed by three weeks on night shift $(N)$. Thus, the shift system is discontinuous with work days ranging from Monday to Friday with weekends off (see Figure 1). This system was criticized by employee representatives because of the 3 weeks of consecutive night shifts and because of its "violation" of generally accepted health-related guidelines for the design of shift systems. ${ }^{5}$

Figure 1

Initial Backward Rotating Shift System (Regime 1; January 2009 until December 2010)

\begin{tabular}{|c|c|c|c|c|c|c|c|c|c|}
\hline Week & 1 & 2 & 3 & 4 & 5 & 6 & 7 & 8 & 9 \\
\hline Shift & D & M & D & M & D & M & N & N & N \\
\hline
\end{tabular}

It was replaced by a system presumably associated with lower health risks for workers. Moreover, this change was considered beneficial from the standpoint of occupational medicine experts expecting the disappearance of the shift-coping problems coming along with the original backward-rotating pattern. The new system started on Jan. $1^{\text {st }}$, 2011 and abandoned the extensive continuous night shifts. Moreover, a forward rotation was implemented. Under the new system workers were also required to work a five day week starting in the morning, then switch to the day shift for week two before working 5 days on the night shift in the third week. In the week following the night shift, the cycle starts again (see Figure 2; note that Friday night shifts finish Saturday morning).

4 Thus, the organizational units that we analyze here include only blue-collar workers with physically demanding jobs. These workers cannot avoid shiftwork, i.e. we can rule out that the composition of the teams that we observe is the result of self-selection of those workers most able to cope with the deleterious effects of shiftwork.

5 The health related guidelines of the Federal Institute for Occupational Safety and Health mandate for example that forward rotating shifts are preferable to backward rotating shifts and that work on weekends is to be avoided (e.g. Beermann 2005). 
Figure 2

New Forward Rotating Shift System (Regime 2; January 2011 until August 2011)

\begin{tabular}{|c|c|c|c|c|c|c|c|c|c|}
\hline Week & 1 & 2 & 3 & 4 & 5 & 6 & 7 & 8 & 9 \\
\hline Shift & M & D & N & M & D & N & M & D & N \\
\hline
\end{tabular}

A few months later, the decision was repealed following worker complaints to the works council and the shift plan was modified again (soon after the workers started to voice their complaints, the chairman of the local works council announced in the regional newspapers that the system would be changed again - without prior consultation with management). This time the rotation direction of the system was changed. The new shift system was implemented following the company's summer break on Aug. $15^{\text {th }}$, 2011 and included a weekly backward rotating long cycle (5 days) system, starting with the morning shift, followed by a week on night shift and then a week on day shift (see Figure 3). The system remained in practice beyond the end of the observation period (December 2011).

Figure 3

New Backward Rotating Shift System (Regime 3; September 2011 until December 2011)

\begin{tabular}{|c|c|c|c|c|c|c|c|c|c|}
\hline Week & 1 & 2 & 3 & 4 & 5 & 6 & 7 & 8 & 9 \\
\hline Shift & M & N & D & M & N & D & M & N & D \\
\hline
\end{tabular}

Although forward rotating systems are considered to provide more recovery time between different shift spells (e.g. Härmä et al. 2006: 71), backward rotation was preferred by workers and their representatives because of its impact on the rather long break on weekends. However, over a complete 3 week shift cycle, both systems (forward vs. backward) provide the same total amount of leisure time at weekends ${ }^{6}$. What is different,

6 Both changes in the shift system had no effect on worker remuneration, because the number of night shift, for which a 30-45 percent premium is paid, remained the same under the three different regimes. Thus, from a purely financial point of view workers should be indifferent between the three regimes. 
however, is the distribution of the leisure periods, resulting in one rather short weekend during the forward rotating cycle.

Moving from night shift to morning shift on the third weekend is associated with 48 hours of leisure time during which workers have to recover from their shifts. Therefore, the time available for recovery (sleep), leisure and social activities is limited on that particular weekend. In contrast, the backward rotating system replaced the night to morning change-over in the third weekend with a night to day adjustment on the second weekend. This gives 56 hours of leisure time. So although the total available time is the same in both systems over a four week period, workers placed a premium on the extra recovery/leisure time derived from the night to day adjustment rather than night to morning. This gave workers more time for recovery and useable leisure time when coming off a night shift. That is, workers would have more time for sleep, home production and 'pure' leisure in the weekend break following a night shift when moving back to a day shift rather than the morning shift. Summarizing, the difference in the distribution in recovery time at weekends - in particular after night shifts - should be considered the main reason for the second adjustment of the shift system ${ }^{7}$. Hence, lack of acceptance by workers and the resulting pressure from the works council induced management to return to a backward rotating system while simultaneously avoiding the problems associated with the original discontinuous system.

Given the evidence in the occupational medicine literature (see section 2 above), we expect absenteeism to be lower in regime 2 (a forward rotating discontinuous cycle) compared to regime 1 (a discontinuous system with six weeks of weekly rotation from morning to day shift followed by three weeks of night shift). Moreover, we expect absence rates for regime 3 to be lower than for regime 1, but higher than for regime 2 .

The available evidence suggests that "quick returns" (short breaks between two different shifts) are indeed associated with shorter sleep duration, cause more disturbed sleep and increase reports of sleepiness and fatigue (Vedaa et al. 2016). 


\section{Data and Descriptive Evidence}

In order to analyze the impact of a change in the shift schedule on absenteeism we use a balanced panel including monthly data on absenteeism from 409 organizational units in one particular plant of a large German automobile company over an extended period of time (January 2009 to December 2011) during which no other changes in e.g. the production process occurred that could have affected worker absenteeism (such as e.g. the start of production of a new car). Our study design has a number of advantages: First, the required information is completely available for all units over a period of 36 consecutive months and, second, the set-up resembles a quasi-experimental design allowing us to identify the effects on worker absenteeism of a move towards a shift schedule that is considered as beneficial by all experts. Our focus on finely tuned data from within a large company enables us to analyze the impact of different shift systems on worker absenteeism with a precision that would be lacking in broader establishmentbased surveys ${ }^{8}$.

Our initial data set included 1,031 organizational units performing a variety of different tasks in the production process (body shop, paint shop, assembly, quality management

8 Admittedly, in an ideal world, randomized control trials should be used to evaluate the impact of different human resource management practices in general and of different shift systems in particular on worker (health) outcomes (such as in e.g. Bloom et al. 2013). Implementing such an experimental design in a German company - be it rather small or very large - is virtually impossible, as the works council will always object, arguing that employees must not be treated like "examination objects". The difficulties of implementing field experiments in firms are discussed in Bandiera, Barankay and Rasul (2011). The reactions of workers (and - if present - their representatives) are likely to be similar in other highly developed economies. To the best of our knowledge, virtually all randomized control trials have been conducted in firms in developing countries (e.g. Mano et al. (2011) in sub-Saharan Africa, Valdivia (2012) in Peru, Bruhn, Karlan and Schoar (2012) as well as Calderon, Cunha and De Giorgi (2013) in Mexico, Giné and Mansuri (2011) in Pakistan; for an extensive review of the literature see Karlan, Knight and Udry (2012). Some of the most widely cited studies in this tradition (e.g. Lazear 2000, Bandiera et al. 2005) also fail to estimate difference-in-difference models as they also lack randomly selected control groups of workers for whom no change in the institutional setting was implemented. 
as well as supporting activities). For half of these units $(n=509)$ information on the number of workers and/or monthly absenteeism was not available at all, leaving us with 522 units. Construction of a balanced panel resulted in a data set including 451 organizational units (information on the remaining 71 units was incomplete because of structural changes in the organization of approximately half of the units (e.g. elimination of some units, creation of new units, mergers of existing units)). Moreover, before estimating our models we performed a series of plausibility checks that led to the elimination of some units with massive outliers (e.g. the number of employees in a particular unit increased by more than $100 \%$ in two months and declined similarly only a month later). Finally, due to the company's data protection regulations we had to exclude units with less than 5 employees, leading to a further reduction in sample size to 409 organizational units. For these units we have the necessary information on the monthly observed absence rate, the monthly projected absence rate and the number of employees. In total, the units in the sample employ some 7,500 workers.

Table 1

Summary Statistics

\begin{tabular}{lcccc}
\hline Variable & Mean & Std. Dev. & Min. & Max. \\
\hline Number of Employees in Unit & 17.99 & 7.69 & 5 & 49 \\
Observed Absence Rate & 6.25 & 5.38 & 0.00 & 56.00 \\
Projected Absence Rate & 3.69 & 0.90 & 1.00 & 7.90 \\
White Collar Absence Rate & 2.45 & 0.51 & 1.50 & 3.70 \\
Shift Regime 1 & 0.67 & - & 0 & 1 \\
Shift Regime 2 & 0.22 & - & 0 & 1 \\
Shift Regime 3 & 0.11 & - & 0 & 1 \\
\hline
\end{tabular}

Number of organizational units: 409

Number of unit-month-observations: 14,724

Fortunately, the limited number of explanatory variables and the resulting lack of controls is not a serious problem because personnel turnover is unusually low at this company (less than $4 \%$ per year) implying that the composition of the teams in the units remains fairly stable over the observation period. Furthermore, the reduction of the 
data set through elimination of units with incomplete data does not bias the results since the characteristics of the excluded units resemble those of the units that are included. The data was obtained from the firm's central human resource reporting system. Monthly absenteeism is measured in percent of regular hours of work. Since we have 409 organizational units in the sample that we observe over a 36 month period, our data set consists of 14,724 unit-month-observations. It appears from Table 1 that the average absence rate is 6.25 percent with a standard deviation of 5.38 percent, which is almost identical to the values reported in a case study from the German metal industry (see Frick, Götzen and Simmons 2013) and the most recent aggregate figures for the German manufacturing sector (see Badura et al. 2012).

Figure 4

Absence Rates by Month

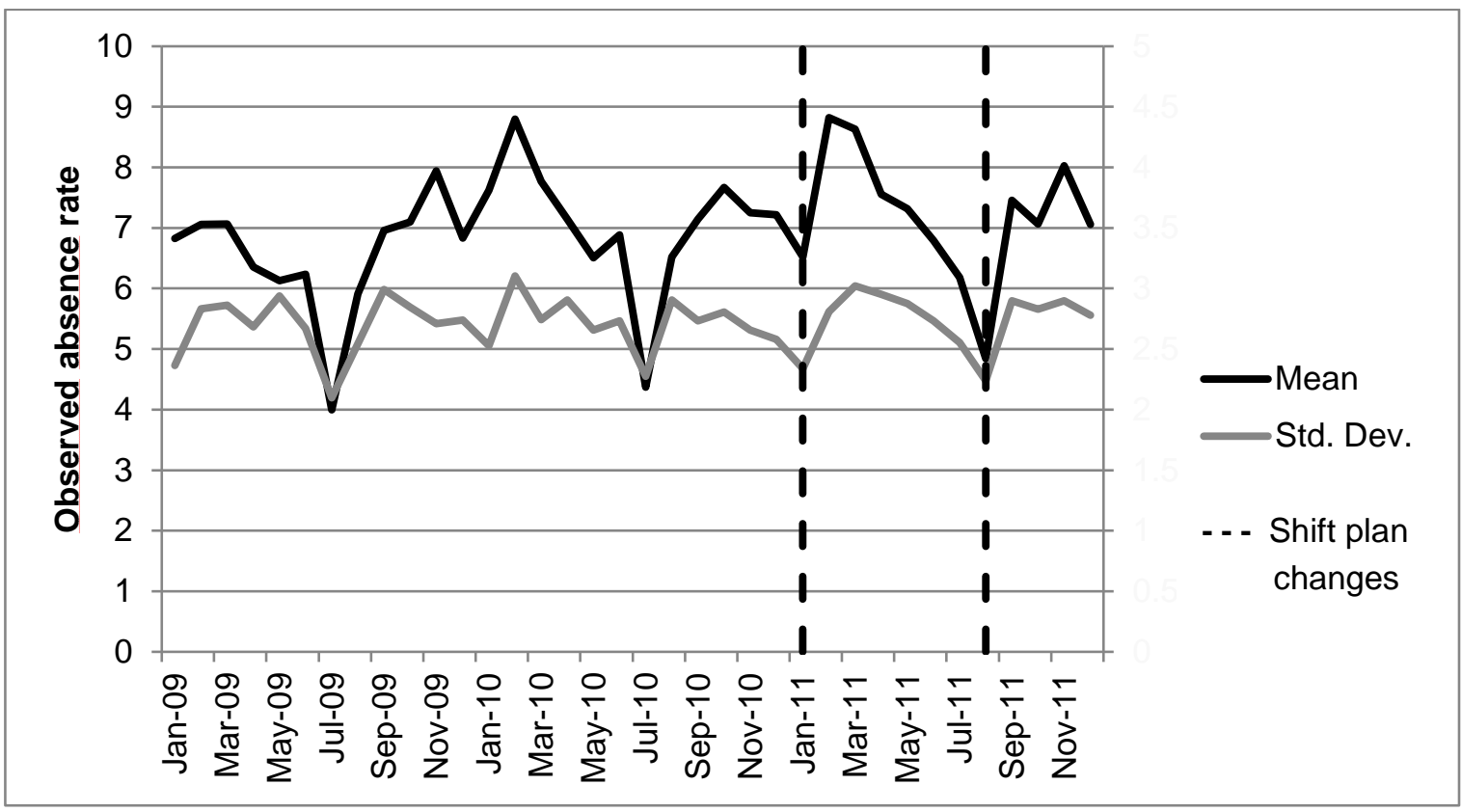

Figure 4 displays the development of the average absence rate over the observation period. As expected, average absenteeism is higher during the winter months ${ }^{9}$. Further-

9 The seasonal pattern is virtually identical with the figures reported in e.g. Badura et al. (2012) for the German manufacturing sector during our observation period. 
more, the dips in absenteeism during the summer months and especially in July or August are not surprising since the plant shuts down production for three weeks during the summer. ${ }^{10}$

A comparison of average absence rates under the three different shift systems (see Figure 5) reveals a particularly low level of absenteeism for 2009 and a high level for 2011. Most observers would attribute this to the uncertainty resulting from the aftermath of the economic crisis: In general, absence rates tend to be lower during economic downturns because a tight labor market (due to high unemployment) offers limited alternatives to workers losing their jobs (i.e. the opportunity costs of losing the job increase) ${ }^{11}$. However, since the company pursues a strict "no layoff policy", these effects must be entirely due to changes in the behavior of temporary agency workers (about 10 percent of the production workers in the plant), who are afraid that their contracts might not be extended due to the recession. Therefore, another-more plausible-explanation is that during the economic crisis, capacity utilization was lower and, therefore, workers were exposed to less stress ${ }^{12}$.

Unfortunately, we cannot empirically distinguish between these two hypotheses. However, we control for seasonal and business cycle effects by estimating our models with 35 month dummies (with September 2010 as the reference month). Moreover, the comparison seems to suggest that absenteeism was higher when the forward rotating shift

10 Due to the working time arrangements of the company a worker on a holiday leave is by definition not "absent", because during his holiday leave he does no "owe" any hours of work to the company. During the time the plant shuts down workers are required to take a holiday leave during which they rarely call in sick. This results in low absence rates during the summer months.

11 Using data from 2006 to 2010 on individual worker productivity from a large firm, Lazear, Shaw and Stanton (2016) demonstrate that during economic downturns workers tend to work harder, i.e. produce more output, to avoid being laid off.

12 Table A1 in the appendix documents considerable changes in the levels of production and employment as well as profitability over the five-year period 2007-2011: First, employment and production have increased considerably and, second, return on sales has reached record levels, resulting in bonus payments of 7,500 Euros per worker and year. Equally important, however, is the massive increase in productivity as measured by cars produced per worker and year. 
system was in use (solid black line). In our econometric analysis we check whether this difference is statistically significant and whether the second change in the shift system was associated with a statistically significant change in absenteeism (not surprisingly, the seasonal pattern of absenteeism is similar to the one in Figure 4) ${ }^{13}$.

Figure 5

Monthly Absence Rates by Shift System

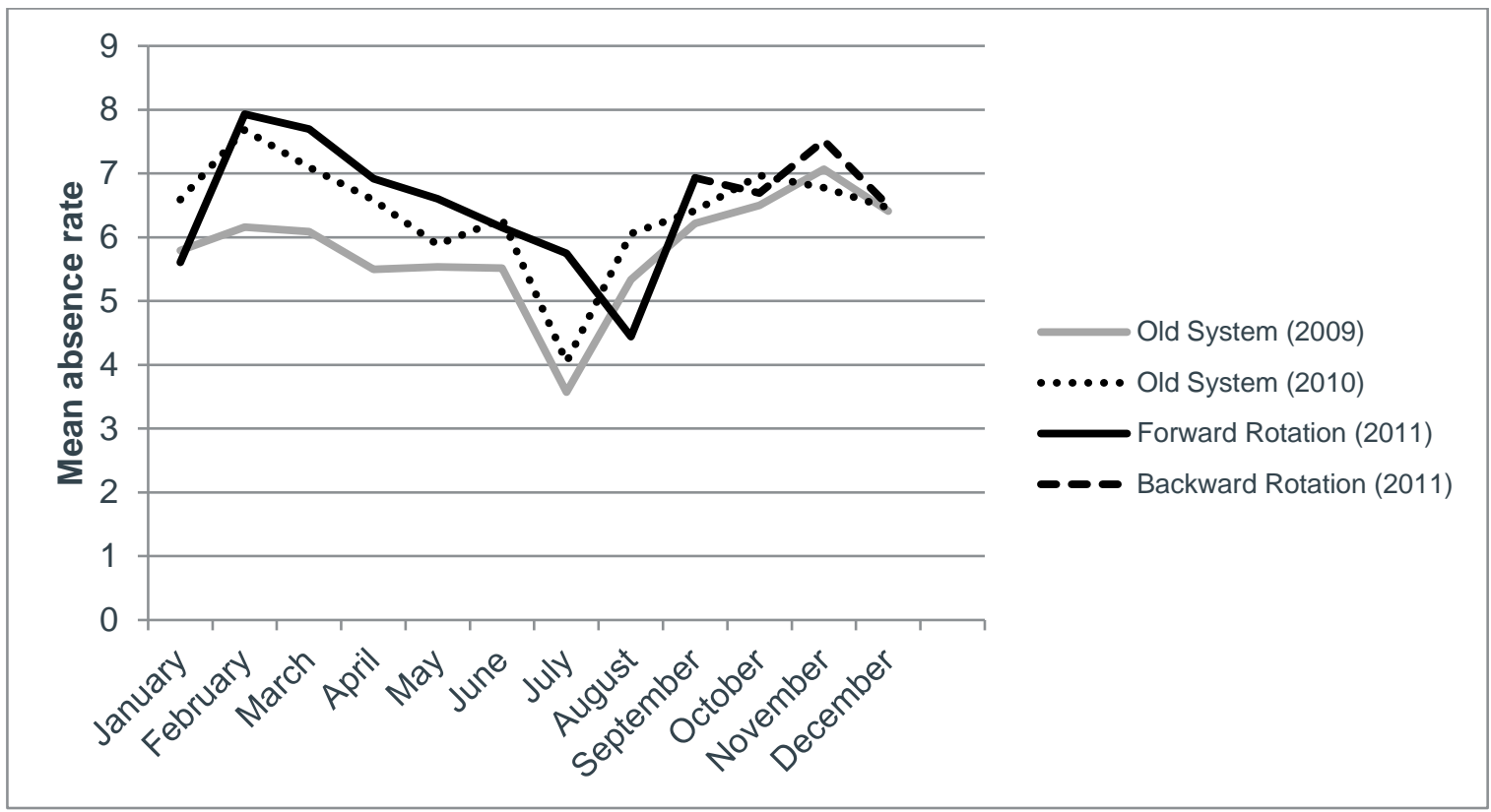

A final observation that warrants some discussion in this context is the difference in the seasonal pattern of the absence rate during the summer months. While for the years 2009 and 2010 the lowest absence rates were recorded for July, in 2011 August was the month with the lowest absence rates. This strange phenomenon is easy to explain: As already mentioned above the plant shuts down for a summer break which, in turn, coincides with the school holidays in the federal state where the plant is located ${ }^{14}$.

13 Kernel density estimates of the observed and the projected absence rate by regime are provided in Figures $\mathrm{A} 1$ and $\mathrm{A} 2$ in the Appendix.

14 The starting date of the summer holidays (which last in general for six weeks) varies by federal state. They start between middle of June (in the Northern states) and end of July (in the Southern states) and end between end of July and middle of September. In 2011, the plant that we study here closed down in August while in 2009 and 2010 it closed down in July already. 


\section{Estimation and Results}

To test for the impact of the two changes in the shift system on absence rates we estimate a generalized linear model (GLM) to account for the proportional nature of our dependent variable. We investigate the effects of shift plans (i.e. "shift regimes") on absenteeism by treating absence rate as a continuous variable. Thus, since our dependent variable is a rate that is bounded between 0 and 1 , we need to estimate a fractional response model along the lines proposed by Papke and Wooldridge $(1996,2008)$ and used by e.g. Frick, Götzen and Simmons (2013) who analyze the impact of semi-autonomous teams and team bonuses on absence rates in a large German steel plant ${ }^{15}$.

In the estimation we include the observed absence rate (calculated as the ratio of missed and contracted monthly working hours) as the dependent and the projected absence rate ${ }^{16}$, the absence rate of white collar workers of the same plant as well as the number of employees in a unit as independent variables (see Table 2). Thus, the data we use here includes only a small number of "internal" explanatory variables, of which the respective units' projected absence rate is by far the most important one. This variable mirrors the differences in socio-demographic characteristics between the units in the sense that projected absenteeism is calculated (and regularly updated) by the company's personnel department taking into account the age, gender and qualification of the units' members: A 35 year-old female production worker for example is expected to

15 The fractional response model is to be preferred over its alternatives because our dependent variable is censored and about 15 percent of the monthly observations are clustered at zero. Papke and Wooldridge apply fractional response model estimation to employee participation rates in pension plans (1996) and school test pass rates (2008). Oberhofer and Pfaffermayr (2009) show that fractional response models can be estimated by general linearized models. Specifically, the results from the fractional response model of Papke and Wooldridge (1996) can be replicated using the glm command in Stata.

16 If a unit exceeds the projected absence rate (this is the case in approximately 60 percent of our observations), this has no consequences. The projected absence rates reflect the composition of the unit and how well it does relative to expectations. 
be absent from work 5.2 percent of the time while a 25 year-old male white-collar employee is expected to be absent from work only 1.0 percent of the time. Since for data protection reasons the socio-demographic characteristics of the units were not made available to us, we consider the projected absence rate a good proxy for the respective units' composition. Overall, the lack of controls appears not to be a serious problem since personnel turnover is - with less than $4 \%$ annually - unusually low at this company. This implies that the composition of the teams in the units remains relatively stable over the entire observation period. Moreover, we include in our estimations month dummies to control for seasonal and business cycle effects (Figure A3 in the Appendix displays the coefficients of the month dummies). What we are most interested in is - of course - the coefficients of the two regime dummies representing the different shift systems, where the initial regime serves as our reference category.

Table 2

GLM Regression of Shift Systems on Absence Rate

\begin{tabular}{|c|c|c|c|}
\hline Variable & Coefficient & $\begin{array}{c}\text { Robust } \\
\text { Standard Error }\end{array}$ & T statistic \\
\hline Number of Employees in Unit & 0.028 & 0.017 & $1.66^{*}$ \\
\hline Projected Absence Rate & 2.014 & 0.157 & $12.82 * * *$ \\
\hline White Collar Absence Rate & 0.007 & 0.186 & $0.04+$ \\
\hline Month-Year Dummies & & Included & \\
\hline Shift Regime 2 & -0.664 & 0.273 & $-2.43^{* *}$ \\
\hline Shift Regime 3 & -0.367 & 0.278 & $-1.32+$ \\
\hline Constant & -1.509 & 0.672 & $-2.25 * *$ \\
\hline \multicolumn{4}{|c|}{$\begin{array}{l}* * * p<0.01 ;{ }^{* *} p<0.05 ; * p<0.10 ;+ \text { not significant } \\
\text { \# reference month is September } 2010\end{array}$} \\
\hline
\end{tabular}

It appears from Table 2 that the majority of the variables included in the estimation are statistically significant. First, absenteeism is slightly higher in larger units (a finding that is in line with the literature, e.g. Dionne and Dostie 2007) and, second, a one percentage point increase in the target rate is associated with a 2.0 percentage point increase in the 
observed absence rate, suggesting that health problems of female and older workers are underestimated by the firm's human resource management department.

Most important, however, are the coefficients of the two regime dummies: The first change in the shift system (from regime 1, including three consecutive weeks of night shift, to regime 2 , a continuous forward rotating long cycle) had a statistically significant and negative effect on absence rates, suggesting that the introduction of the new (and presumably "healthy") shift system induced a decrease in the monthly absence rate by 0.66 percentage points ${ }^{17}$. On first impression, the second regime change (from the continuous forward rotating to a similar backward rotating system, i.e. regime 3) was also associated with a lower absence rate compared to the initial level. However, the latter coefficient failed to reach statistical significance. Moreover, the coefficients of the two regime shift dummies are significantly different, suggesting that the forward rotating shift schedule is indeed associated with lower absenteeism than the backward rotating system that replaced it. Summarizing, given the workers' opposition against regime 2 , our findings suggest that they care more about the distribution of their recovery/leisure time than about the long-term health effects of alternative shift systems which, in turn, indicates that workers may discount future health problems.

Since the two different shift regimes were imposed on all production units, we do not have a natural experiment design. However, we do know the absence rate of full-time white-collar workers performing regular daytime work. We therefore introduced the monthly white-collar absence rate as an additional control variable and found that this returned an insignificant coefficient. Moreover, the white-collar absence rate was found

17 Estimation of a fixed effects model with robust standard errors delivers almost identical results. These are available from the authors on request. The most important finding here is that the coefficients of our regime dummies retain their sign as well as their magnitude. The coefficient of the predicted absence rate, however, loses its statistical significance in the fixed effects estimation which appears plausible because the projections are adjusted at the beginning of each calendar year based on changes in the gender composition and the age and qualification structure of the units (and remain constant for the rest of the particular year), suggesting that projected absenteeism is a (more or less) time-invariant variable. 
not to vary with changes in production worker shift regime. This rules out the possibility that both white-collar and blue-collar worker types were affected by some unknown confounding factor occurring at the same time as the changes in the production worker shift pattern.

Table 3

GLM Regression of Shift Systems on Absence Rate by Unit Size and by Level of Absenteeism

\begin{tabular}{|c|c|c|c|c|}
\hline Variable & $\begin{array}{l}\text { Small Units } \\
\text { (less than } 18 \\
\text { employees) }\end{array}$ & $\begin{array}{l}\text { Large Units } \\
\text { (18 and } \\
\text { more em- } \\
\text { ployees) }\end{array}$ & $\begin{array}{c}\text { Low Absen- } \\
\text { teeism (less } \\
\text { than } 6.25 \\
\text { percent) }\end{array}$ & $\begin{array}{l}\text { High Absentee- } \\
\text { ism ( } 6.25 \text { per- } \\
\text { cent and more) }\end{array}$ \\
\hline Unit Size & $0.120 *$ & $0.010+$ & $0.033 * * *$ & $-0.055^{* *}$ \\
\hline Target Rate & $1.937 * * *$ & $1.725 * * *$ & $0.798 * * *$ & $1.485^{* * *}$ \\
\hline White Collar Absence Rate & $-0.001+$ & $-0.041+$ & $0.492 * *$ & $-0.518^{*}$ \\
\hline Month-Year Dummies ${ }^{\#}$ & \multicolumn{4}{|c|}{ Included } \\
\hline Shift Regime 2 & $-0.588+$ & $-0.775 * * *$ & $-0.613 * * *$ & $-0.467+$ \\
\hline Shift Regime 3 & $-0.560+$ & $-0.328+$ & $-0.177+$ & $-0.447+$ \\
\hline Constant & $-2.558 * * *$ & $-0.423+$ & $-0.308+$ & $4.371 * * *$ \\
\hline \multicolumn{5}{|c|}{$\begin{array}{l}* * * p<0.01 ; * * p<0.05 ; * p<0.10 ;+ \text { not significant } \\
\text { \# reference month is September } 2010\end{array}$} \\
\hline
\end{tabular}

Estimating the model presented above separately for small and large units and for those with above and below average absenteeism, it appears that the positive effect of the forward rotating shift regime is restricted to the large units on the one hand and to those with below average absence rates on the other hand. The latter finding is due to the company's no layoff policy, which in practice means that employees with chronic health problems are relocated to production units with physically less demanding tasks, leading to the paradox, that the least demanding jobs are associated with the highest absence rates - because they are being done by the least healthy persons. Thus, employees with chronic health problems are less likely to benefit from the forward rotating shift schedule that is considered by occupational medicine specialists as being less detrimental to worker health (the projected absence rate in the units with above average absenteeism 
is significantly higher than in the other units, suggesting that the workers in the former units are much older).

\section{Summary and Conclusions}

Absenteeism has always been (and continues to be) a "top priority" in the large German automobile company that we study here. Apart from changes in shift schedules, management has for example implemented various health training measures in selected service units to reduce worker absenteeism. The main result in the present context is that the change from a shift system considered as ergonomically unfavorable (as it is characterized by backward rotation and three continuous weeks of night shifts) to a (forward rotating) schedule that is considered an improvement from a health perspective is associated with a statistically significant decrease in monthly absence rates. This decrease is completely offset by a second modification of the shift system. Changing the direction of rotation (from forward to backward, i.e. from a system considered as advantageous from a health perspective to one that is associated with higher health risks for workers by medical experts) is associated with an increase in monthly absence rates back to original levels. This is worrying for the company. Both the initial and the final system are backward rotating. Compared with the original system, the final regime is considered to expose workers to reduced health risks due to its shorter night shift cycle and as such ought to deliver a lower absence rate. Yet this has not happened. Moreover, workers seem to have increased their utility through a more desirable distribution of recovery/leisure over weekends and also reduced their hours of actual work through greater absenteeism - reducing the actual "dose" of shift work - hence lowering their disutility of work. Unfortunately, we are unable to determine whether the greater absence rate under the third and final regime compared to the second was due to minor sickness, major sickness or shirking behavior.

According to our estimations, the introduction of an ergonomically advantageous shift system is associated with a 0.66 percentage point decrease in monthly absenteeism (a 
decline of more than 10\%). Evaluated at the mean of the two coefficients we estimate the benefits due to the initial decrease in absenteeism at about $€ 2.3$ million (about $€ 300,000$ per month). Since the organizational units included in our sample comprise only $30 \%$ of the workforce, the total returns are more than three times as high (nearly $€ 7.7$ million). ${ }^{18}$ However, these benefits were forfeited by changing the shift system again after a rather short period of time in response to (specific groups of) workers expressing their discontent with the continuous forward rotating shift system. ${ }^{19}$ Moreover, the company is since 2011 discussing implementations of other shift systems that are particularly designed to foster employee health and fitness by changing to a short forward-rotating cycle and by adding a fourth shift. We plan to study the impact of this new ("ergonomic") shift system as soon as longitudinal data for a similarly large number of organizational units is available.

In German firms, the works council typically negotiates over a bundle of company policies. On some issues, it has the right to information and consultation, on others a veto power over management initiatives, on still others the right to codetermination in the design and implementation of policy. Its rights are strongest in social and personnel matters such as the introduction of new payment methods, the introduction of technical devices designed to monitor employee performance and - particularly important in our context - the allocation of working hours, including the design of the shift schedule to be used ${ }^{20}$.

18 Calculated as hours lost due to additional absenteeism times gross hourly wage costs per workers.

19 We have also investigated in more detail the possibility of a "Hawthorne effect" (e.g. Bloombaum 1983; Franke and Kaul 1978; Jones 1992; Levitt and List 2011). It has until recently been taken for granted that any organizational change will eventually lead to a short-term change in employee behavior independent of the nature of the change and that this change will decrease over time. In our estimations including a linear time trend that starts with the implementation of each of the regime changes, we fail to find any such effect (the results of these estimations are available from the authors upon request).

20 The works council also has consultation rights, though not as strong, in matters such as changes in equipment and working methods that affect job requirements, decisions relating to manpower planning and structural alterations to the plant. Its participation rights in financial and economic matters cover information provision. Moreover, the council can bargain over social compensation plans. It has 
As shiftwork can create troublesome problems for the employees' health and family life, the works council has a specific role in the design and use of this working time arrangement in the sense that it can reconcile the conflicting interests of management and employees. Duncan and Stafford (1980), for example, argue that a reduction in the disamenities of shiftwork is a workplace public good as it has aspects of non-rival consumption shared by many workers in the establishment. Thus, communicating aggregated worker preferences to management can help to design and implement shift schedules that are more acceptable to the workforce - even at the price of an increase in the percentage of workers suffering from long-term health problems.

the right to demand compensation for the dislocation caused by plant closings and major changes in the company's organization. 


\section{Appendix}

Table A1

Employment, Production, and Profitability of Automobile Company

\begin{tabular}{lcccc}
\hline Year & $\begin{array}{c}\text { Employment } \\
\text { Germany, in } \\
1,000)\end{array}$ & $\begin{array}{c}\text { Production } \\
\text { (Germany, in } \\
1,000)\end{array}$ & $\begin{array}{c}\text { Cars per Em- } \\
\text { ployee }\end{array}$ & $\begin{array}{c}\text { Return on } \\
\text { Sales }\end{array}$ \\
\hline 2007 & 175 & 2,086 & 11.9 & 6.0 \\
2008 & 178 & 2,146 & 12.1 & 5.8 \\
2009 & 173 & 1,938 & 11.2 & 1.2 \\
2010 & 178 & 2,115 & 11.9 & 7.1 \\
2011 & 196 & 2,640 & 13.5 & 11.9 \\
\hline
\end{tabular}

Source: Annual Reports 
Figure A1

Density Plot of Absence Rate by Shift Regime

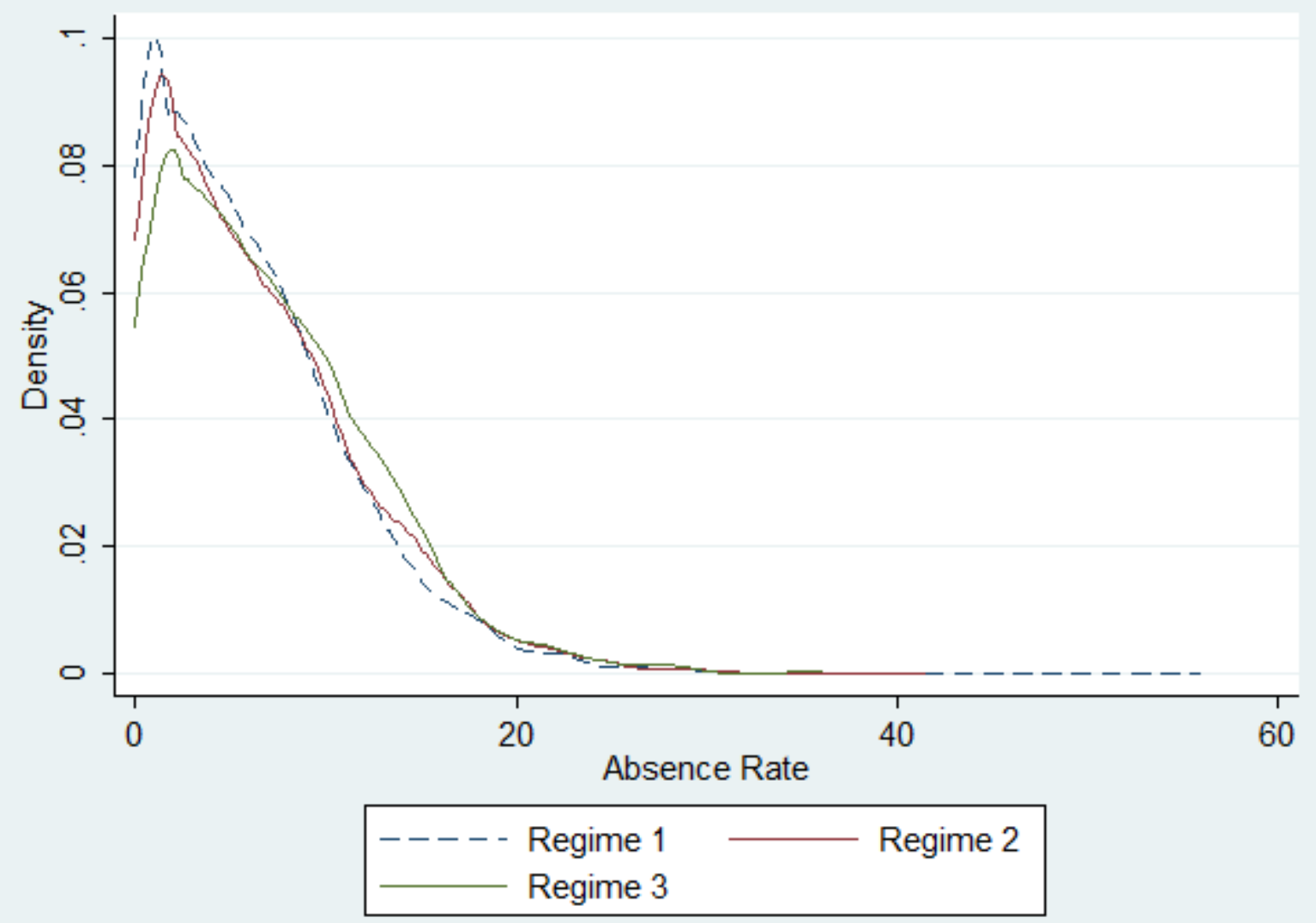


Figure A2

Density Plot of Target Rate by Shift Regime

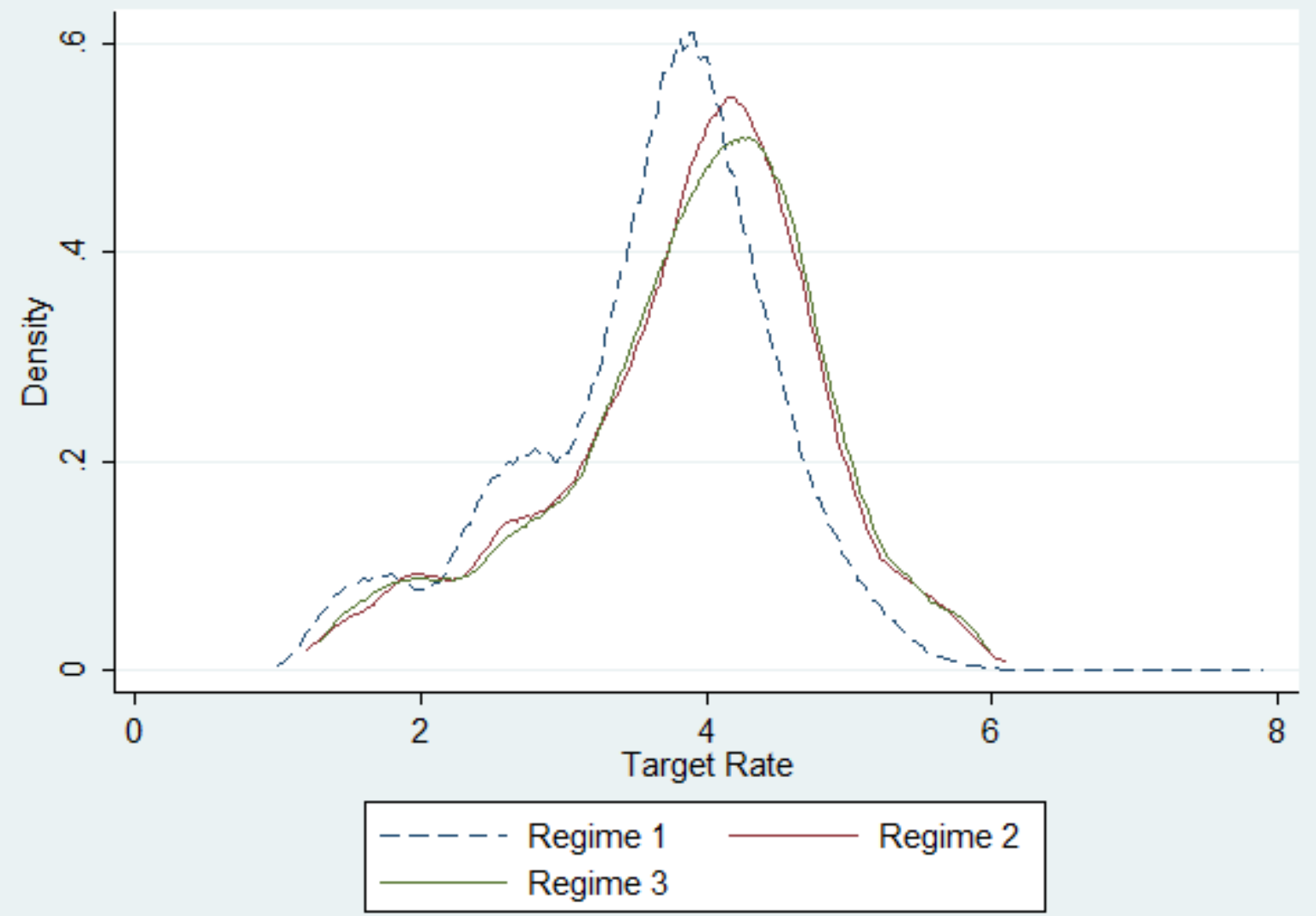


Figure A3

Coefficients of Month Dummies

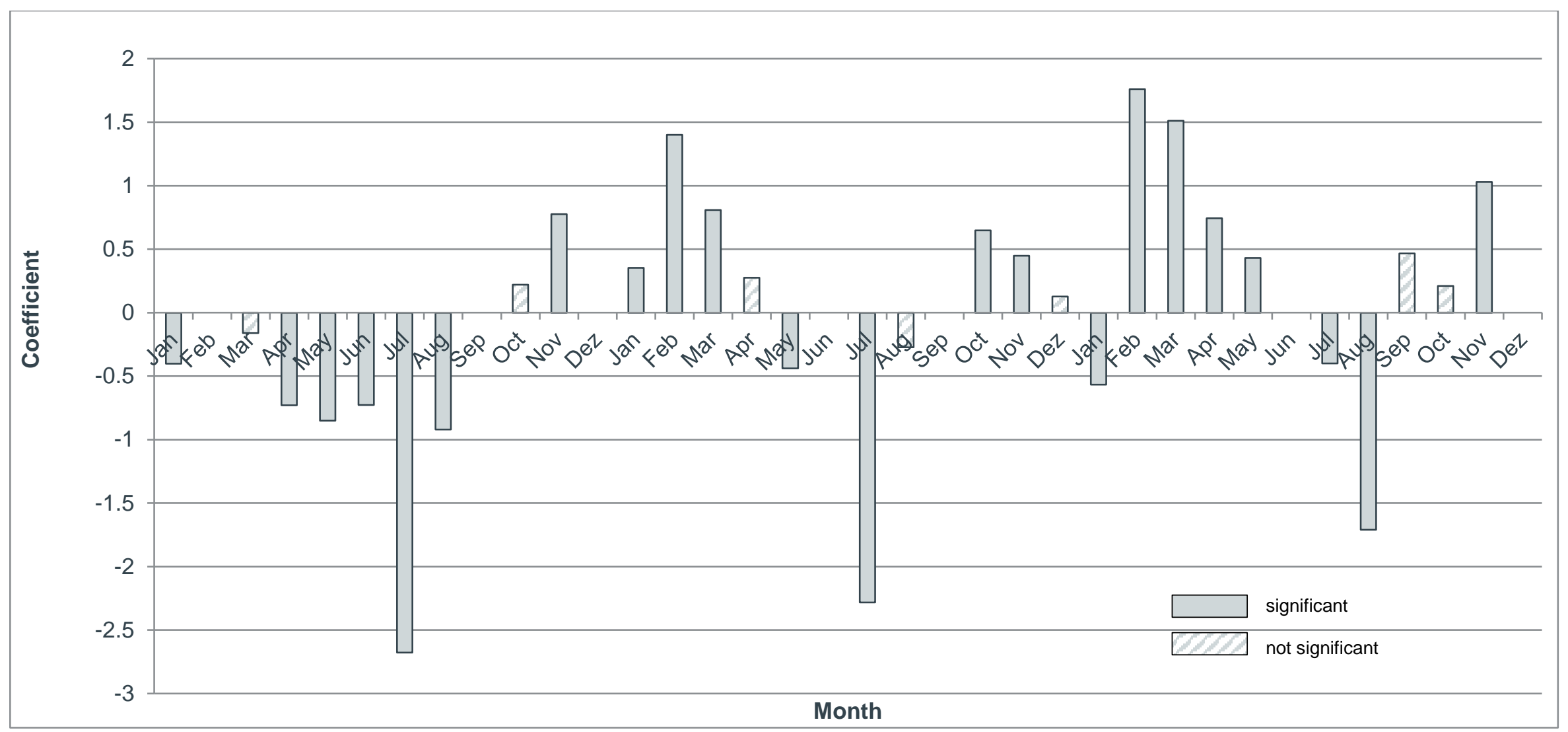




\section{Literature}

Akerstedt, T. (2003): Shift Work and Disturbed Sleep/Wakefulness. Occupational Medicine, 53, pp. 89-94.

Angersbach, D., P. Knauth, H. Loskant, M.J. Korvonen, K. Undeutsch and J. Rutenfranz (1980): A Retrospective Cohort Study Comparing Complaints and Diseases in Day and Shift Workers. International Archives of Occupational and Environmental Health, 45, pp. 127-140.

Askildsen, J.E., B.H. Baltagi and T.H. Holmas (2003): Wage Policy in the Health Care Sector: A Panel Data Analysis of Nurses' Labour Supply. Health Economics, 12, pp. 705719.

Backes-Gellner, U., E. Bollschweiler, A.H. Hölscher and A. Krings (1999): Alternative Arbeitszeitmodelle und die Qualität der Patientenversorgung - eine empirische Studie auf chirurgischen Intensivstationen. Zeitschrift für Betriebswirtschaft, 69, pp. 125146.

Badura, B., A. Ducki, H. Schröder, J. Klose and M. Meyer (eds.): Fehlzeiten-Report 2012, Berlin: Springer.

Bambra, C.L., M.H. Whitehead, A.J. Sowden, J. Akers and M.P. Petticrew (2008): Shifting Schedules: The Health Effects of Reorganizing Shift Work. American Journal of Preventive Medicine, 34, pp. 427-434.

Bandiera, O., I. Barankay and I. Rasul (2005): Social Preferences and the Response to Incentives: Evidence from Personnel Data. Quarterly Journal of Economics, 120, pp. 917-962

Bandiera, O., I. Barankay and I. Rasul (2011): Field Experiments with Firms. Journal of Economic Perspectives, 25, pp. 63-82.

Beermann, B. (2005): Leitfaden zur Einführung und Gestaltung von Nacht- und Schichtarbeit, Dortmund: Federal Institute for Occupational Safety and Health.

Blau, G. and M. Lunz (1999): Testing the Impact of Shift Schedules on Organizational Variables. Journal of Organizational Behavior, 20, pp. 933-942.

Bloom, N. and J. Van Reenen (2010): Human Resource Management and Productivity. NBER Working Paper No. 16019. Cambridge, MA: National Bureau of Economic Research.

Bloom, N., B. Eifert, A. Mahajan, D. McKenzie and J. Roberts (2013): Does Management Matter? Evidence from India. Quarterly Journal of Economics, 128, pp. 1-51.

Bloombaum, M. (1983): The Hawthorne Experiments: A Critique and Analysis of the First Statistical Interpretation by Franke and Kaul. Sociological Perspectives, 26, pp. 71-88.

Brachet, T., G. David and A. Drechsler (2012): The Effect of Shift Structure on Performance. American Economic Journal: Applied Economics, 4, pp. 219-246.

Böckerman, J. and P. Ilmakunnas (2008): Interaction of Working Conditions, Job Satisfaction, and Sickness Absences: Evidence from a Representative Sample of Employees. Social Science \& Medicine, 67, pp. 520-528.

Bruhn, M., D. Karlan and A. Schoar (2012): The Impact of Consulting Services on Small and Medium Enterprises: Evidence from a Randomized Trial in Mexico, Yale Economics Department Working Paper No. 100. 
Calderon, G., J.N. Cunha and G. De Giorgi (2013): Business Literacy and Development: Evidence from a Randomized Control Trial in Rural Mexico, Working Paper 19740, Cambridge, MA: National Bureau of Economic Research.

Chaudhury, M. and I. Ng (1992): Absenteeism Predictors: Least Squares, Rank Regression and Model Selection Results. Canadian Journal of Economics, 25, pp. 615-635.

Costa, G. (1996): The Impact of Shift and Night Work on Health. Applied Ergonomics, 27, pp. 9-16.

Costa, G. (2003): Shift Work and Occupational Medicine: An Overview. Occupational Medicine, 53, pp. 83-88.

Costa, G. (2010): Shift Work and Health: Current Problems and Preventive Actions: Safety and Health at Work, 1, pp. 112-123.

Czeisler, C.A., M.C. Moore-Ede and R.M. Coleman (1982): Rotating Shift Work Schedules that Disrupt Sleep are Improved by Applying Circadian Principles. Science, 217, pp. 460-463.

De Valck, E., S. Quanten, D. Berckmans and R. Cluydts (2007): Simulator Driving Performance, Subjective Happiness and Salivary Cortisol in a Fast-Forward versus a SlowBackward Rotating Shift System. Scandinavian Journal of Work, Environment \& Health, 33, pp. 51-57.

Dall'Ora, C., J. Bell, A. Recio-Sancedo and P. Griffiths (2016): Characteristics of Shift Work and Its Impact on Employee Performance and Wellbeing: A Literature Review. International Journal of Nursing Studies, 57, pp. 12-27.

Dionne, G. and B. Dostie (2007): New Evidence on the Determinants of Absenteeism Using Linked Employer-Employee Data. Industrial and Labor Relations Review, 61, pp. 108-120.

Drago, R. and M. Wooden (1992): The Determinants of Labor Absence: Economic Factors and Workgroup Norms across Countries. Industrial and Labor Relations Review, 45, pp. 764-778.

Duncan, G. and F. Stafford (1980): Do Union members Receive Compensating Wage Differentials? American Economic Review, 70, pp. 355-371.

Frick, B., U. Götzen and R. Simmons (2013): The Hidden Costs of High Performance Work Practices: Empirical Evidence from a Large German Steel Company. Industrial and Labor Relations Review, 66, pp. 198-224.

Franke, R.H. and J.D. Kaul (1978): The Hawthorne Experiments: First Statistical Interpretation. American Sociological Review, 43, pp. 623-643.

German Federal Statistical Office (2013): Bevölkerung und Erwerbstätigkeit, Fachserie 1, Reihe 4.1.2., Wiesbaden.

Giné, X. and G. Mansuri (2011): Money or Ideas? A Field Experiment on Constraints to Entrepreneurship in Rural Pakistan, Working Paper.

Gray, M., L. Qu, D. Stanton and R. Weston (2004): Long Work Hours and the Wellbeing of Fathers and their Families. Australian Journal of Labour Economic, 7, pp. 255-273.

Hänecke, K., S. Tiedemann, F. Nachreiner and H. Grzech-Sukalo (1998): Accident Risk as a Function of Hour at Work and Time of Day as Determined from Accident Data and Exposure Models for the German Working Population. Scandinavian Journal of Work and Environmental Health, 24, pp. 43-48. 
Härmä, M., T. Hakola, I. Kandolin, M. Sallinen, J. Virkkala, A. Bonnefond and P. Mutanen (2006): A Controlled Intervention Study on the Effects of a Very Rapidly Forward Rotating Shift System on Sleep-Wakefulness and Well-Being among Young and Elderly Shift Workers. International Journal of Psychophysiology, 59, pp. 70-79.

Harrington, J.M. (2001): Health Effects of Shift Work and Extended Hours of Work. Occupational and Environmental Medicine, 58, pp. 68-72.

Ichniowski, C. and K. Shaw (2013): Insider Econometrics: Studies on How Management Matters. In: Gibbons, R. and J. Roberts (eds.): Handbook of Organizational Economics, Princeton, NJ: Princeton University Press, pp. 263-311.

Ichniowski, C., K. Shaw and G. Prennushi (1997): The Effects of Human Resource Management Practices on Productivity: A Study of Steel Finishing Lines. American Economic Review, 87, pp. 291-313.

Jansen, N.W.H., I. Kant, F.J.N. Nijhus, G.M.H. Swaen and T.S. Kristensen (2004): Impact of Worktime Arrangements on Work-Home Interference among Dutch Employees. Scandinavian Journal of Work and Environmental Health, 30, pp. 139-148.

Jirjahn, U. (2008): On the Determinants of Shift Work and Overtime Work: Evidence from German Establishment Data. British Journal of Industrial Relations, 46, pp. 133-168.

Jones, S.R.G. (1992): Was There a Hawthorne Effect? American Journal of Sociology, 98, pp. 451-468.

Karlan, D., R. Knight and C. Udry (2012): Hoping to Win, Expected to Lose: Theory and Lessons on Micro Enterprise Development, Working Paper 18325, Cambridge, MA: National Bureau of Economic Research.

Kecklund, G. and J. Axelsson (2016): Health Consequences of Shift Work and Insufficient Sleep. British Medical Journal, 355, i.5210.

Kecklund, G., C.P. Eriksen and T. Akerstedt (2008): Police Officers Attitudes to Different Shift Systems: Association with Age, Present Shift Schedule, Health and Sleep/Wake Complaints. Applied Ergonomics, 38, pp. 565-571.

Knauth, P., K. Landau, C. Dröge, M. Schwittek, M. Widynski and J. Rutenfranz (1980): Duration of Sleep Depending on the Type of Shift Work. International Archives of Occupational and Environmental Health, 46, pp. 167-177.

Koller, M. (1983): Health Risks Related to Shift Work. International Archives of Occupational and Environmental Health, 53, pp. 59-75.

Kostiuk, P.F. (1990): Compensating Differentials for Shift Work. Journal of Political Economy, 98, pp. 1054-1075.

Lazear, E.P. (2000): Performance Pay and Productivity. American Economic Review, 90, pp. 1346-1361.

Lazear, E.P. and K. Shaw (2007): Personnel Economics: The Economists' View of Human Resources. Journal of Economic Perspectives, 21, pp. 91-114.

Lazear, E.P., K.L. Shaw and C. Stanton (2016): Making Do with Less: Working Harder During Recessions. Journal of Labor Economics, 34, pp. 333-360.

Levitt, S.D. and J.A. List (2011): Was There Really a Hawthorne Effect at the Hawthorne Plant? An Analysis of the Original Illumination Experiment. American Economic Journal: Applied Economics, 3, pp. 224-238.

Mano, Y., A. Iddrisu, Y. Yoshino and T. Sonobe (2011): How Can Micro and Small Enterprises in Sub-Saharan Africa Become More Productive? The Impacts of Experimental 
Basic Managerial Training, Policy Research Working Paper Series No. 5755, The World Bank.

Martens, M.F.J., F.J.N. Nijhus, M.P.J. van Boxtel and J.A. Knottnerus (1999): Flexible Work Schedules and Mental and Physical Health. A Study of a Working Population with Non-traditional Working Hours. Journal of Organizational Behavior, 20, pp. 3546.

Nakata, A., T. Haratani, M. Takahashi, N. Kawakami, H. Arito, F. Kobayashi, Y. Fujioka, S. Fukui and S. Araki (2004): Association of Sickness Absence with Poor Sleep and Depressive Symptoms in Shift Workers. Chronobiology International, 21, pp. 899-912.

Oberhofer, H. and M. Pfaffermayr (2009): Fractional Response Models - A Replication Exercise of Papke and Wooldridge (1996), Working Paper 2009-02, Department of Economics, University of Innsbruck.

Papke, L.E. and J.M. Wooldridge (1996): Econometric Models for Fractional Response Variables with an Application to 401(k) Plan Participation Rates. Journal of Applied Econometrics, 11, pp. 619-632.

Papke, L.E. and J.M. Wooldridge (2008): Panel Data Methods for Fractional Response Variables with an Application to Test Pass Scores. Journal of Econometrics, 145, pp. 121-133.

Petru, R., M. Wittmann, D. Nowak, B. Birkholz and P. Angerer (2005): Effects of Working Permanent Night Shifts and Two Shifts on Cognitive and Psychomotor Performance. International Archives of Occupational and Environmental Health, 78, pp. 109-116.

Root, L.S. and L.P. Wooten (2008): Time Out for Family: Shift Work, Fathers and Sports. Human Resource Management, 47, pp. 481-499.

Shaw, K. (2009): Insider Econometrics: A Roadmap with Stops Along the Way. Labour Economics, 16, pp. 607-617.

Shen, J. and B. Dicker (2008): The Impacts of Shiftwork on Employees. International Journal of Human Resource Management, 19, pp. 392-405.

Wagstaff, A.S. and J.-A. Sigstad-Lie (2011): Shift and Night Work and Long Working Hours: A Systematic Review of Safety Implications. Scandinavian Journal of Work, Environment \& Health, 37, pp. 173-185.

Valdivia, M. (2012): Training or Technical Assistance for Female Entrepreneurship? Evidence from a Field Experiment in Peru, GRADE Working Paper.

Van Ammelsvoort, L.G., N.W. Jansen, G.M. Swaen, P.A. Van den Brandt and I. Kant (2004): Direction of Shift Rotation among Three-Shift Workers in Relation to Physiological Health and Work-Family Conflict. Scandinavian Journal of Work, Environment \& Health, 30, pp. 149-156.

Vangelova, K. (2008): The Effect of Shift Rotation on Variations of Cortisol, Fatigue and Sleep in Sound Engineers. Industrial Health, 46, pp. 490-493.

Vedaa, O., A. Harris, B. Björvatn, S. Waage, B. Sivertsen, P. Tucker and S. Pallesen (2016): Systematic Review of the Relationship between Quick Returns in Rotating Shift Work and Health-Related Outcomes. Ergonomics, 59, pp. 1-14.

Viitasalo, K., E. Kuosma, J. Laitinen and M. Härmä (2008): Effects of Shift Rotation and the Flexibility of a Shift System on Daytime Alertness and Cardiovascular Risk Factor. Scandinavian Journal of Work, Environment \& Health, 34, pp. 198-205. 